\title{
Una mujer con una extraña alopecia por quimioterapia
}

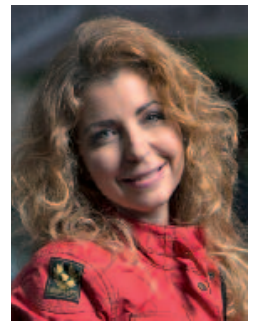

Elena González-Guerra Doctora en Medicina y Cirugía.

Médico adjunto.

Servicio de Dermatología. Hospital Clínico

San Carlos. Madrid.

Profesora asociada de Dermatología.

Facultad de Medicina. Universidad Complutense de Madrid.

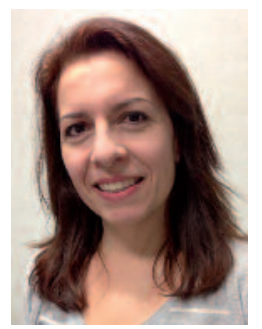

\section{Laura Lema Roso}

Licenciada en Medicina y Cirugía por la Universidad Autónoma de Barcelona. Médico adjunto. Servicio de Oncología Médica.

Hospital Universitario 12 de Octubre. Madrid.
Mi paciente es una mujer con una extraña alopecia por quimioterapia. A sus 63 años, se encontraba en los comienzos del tratamiento de su cáncer de mama metastásico, con un moderno fármaco —eribulina- y quería atención dermatológica para prevenir y cuidar en lo posible los probables efectos secundarios. En la exploración, pude advertir el inicio de un efluvio del cabello, con un signo de la tracción positivo (fig. 1), que dibujaba una alopecia difusa por quimioterapia (fig. 2).

A menudo, veo enfermos oncológicos y, muy frecuentemente, mujeres en tratamiento por cáncer de mama que están recibiendo tratamiento quimioterápico. No me extrañaba, por lo tanto, la alopecia inducida por quimioterapia (CIA por sus siglas en inglés). Al mes, mi paciente presentaba una CIA característica

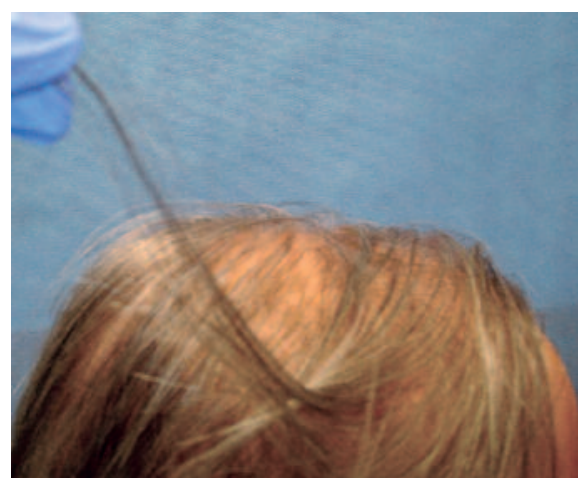

Figura 1. Signo de la tracción (Sabouraud) positivo. (fig. 3), con discreta afectación de cejas, pero no de pestañas. También pude observar una hiperqueratosis palmoplantar, que correspondía a una eritrodisestesia por quimioterapia (fig. 4) que arrastraba desde hacía tiempo por los tratamientos previos. Pero mi sorpresa fue grande cuando, pese a continuar con el mismo medi-

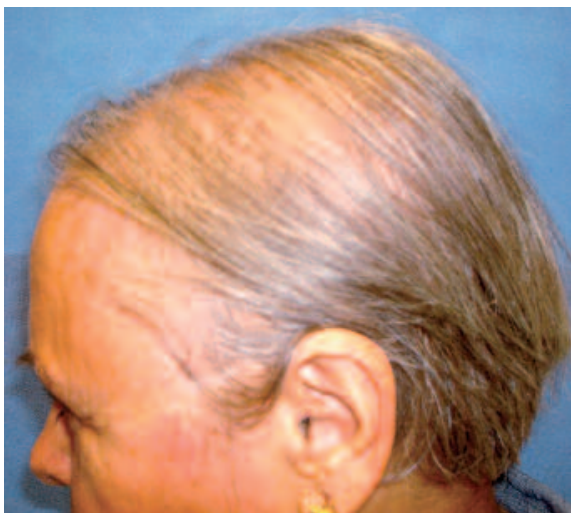

Figura 2. Efluvio anágeno incipiente.

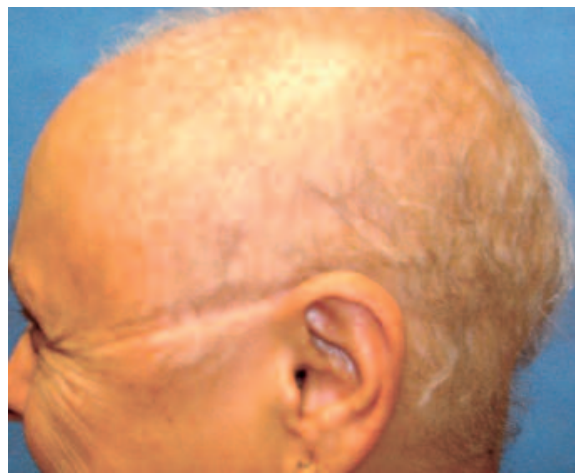

Figura 3. Alopecia por quimioterapia (CIA) por eribulina. 


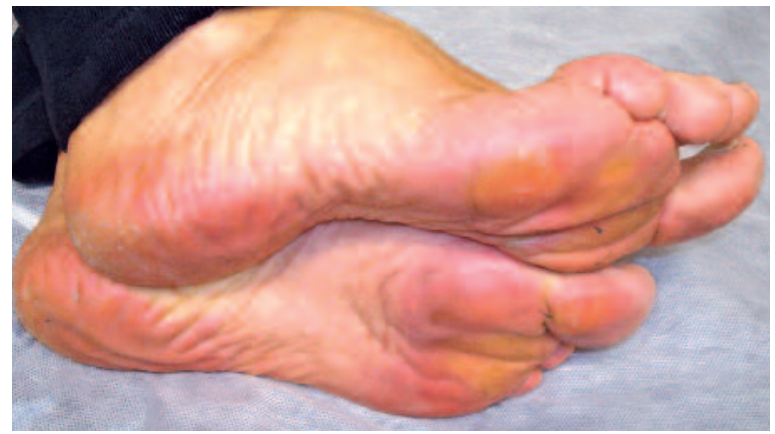

Figura 4. Eritrodisestesia palmoplantar.

camento, un mes después, el pelo había comenzado a crecer, y repoblándose por completo en el momento de la visita (fig. 5). Mi paciente sobrellevaba muy bien «estos ciclos que no la dejaban calva», según sus propias palabras.

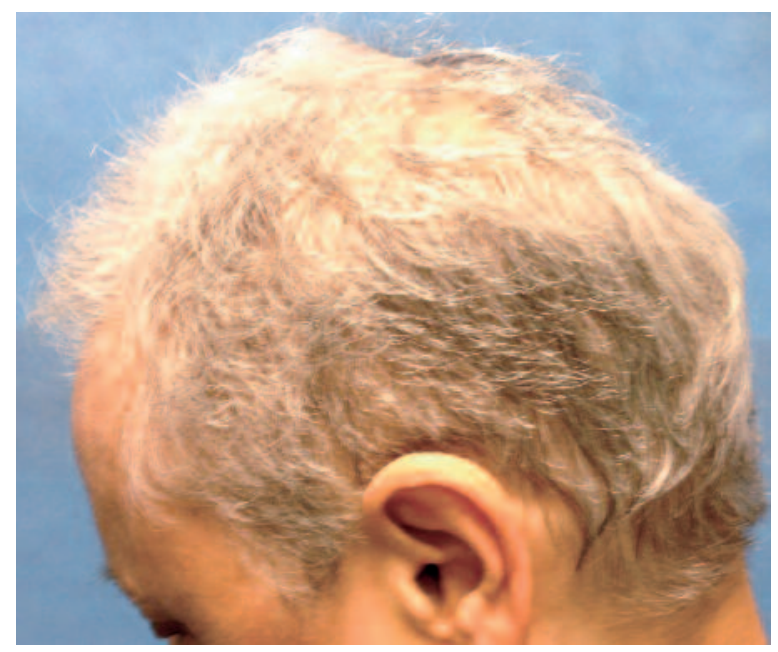

Figura 5. Repoblación capilar durante el tratamiento con eribulina.

El cáncer de mama es el tumor femenino más frecuente en el mundo. Solo en España, se diagnostican más de 26000 casos nuevos al año ${ }^{1}$, aunque la supervivencia libre de progresión y la global se han incrementado intensamente ${ }^{2}$.

En pacientes con cáncer de mama local inoperable o recaída a distancia, el tratamiento sistémico es la principal opción. La elección de dicho tratamiento puede depender de varios factores como la biología del tumor, los tratamientos previos, la duración del intervalo libre de enfermedad, las comorbilidades, etcétera.

Uno de estos fármacos es la eribulina. Se trata de un fármaco inhibidor no taxano de la dinámica de los microtúbulos que pertenece a la clase de antineoplásicos de la halicondrina. Es un análogo sintético estructuralmente simplificado de la halicondrina $\mathrm{B}$, un producto natural aislado de la esponja marina Halichondria okadai. Ejerce sus efectos a través de un mecanismo antimitótico basado en la tubulina que da lugar al bloqueo del ciclo celular G2/M, a la disrupción de los husos mitóticos y, en última instancia, a la apoptosis celular después del bloqueo mitótico prolongado.

Está indicado en monoterapia para pacientes con cáncer de mama localmente avanzado o metastásico con progresión de la enfermedad después de, al menos, dos regímenes de quimioterapia para la enfermedad avanzada. La terapia previa debe haber incluido una antraciclina y un taxano, a no ser que estos tratamientos no fueran adecuados para el paciente ${ }^{3}$.

Los ensayos clínicos que le han permitido la indicación no han podido identificar el subgrupo dependiendo de receptores hormonales y del HER2 (receptor 2 del factor de crecimiento epidérmico humano) que pueda beneficiarse más del tratamiento, por lo que el estado de estos no es criterio de restricción actualmente.

La eribulina es un fármaco de administración endovenosa que se infunde los días 1 y 8 de cada 21 días y no requiere premedicación ni tratamientos antieméticos acompañantes.

En los estudios clínicos realizados con eribulina, las reacciones adversas que se consideraron muy frecuentes fueron mielosupresión, anorexia, neuropatía periférica, astenia, náuseas, diarrea, estreñimiento, artralgias, mialgias y alope$\mathrm{cia}^{4,5}$.

Así, en el estudio EMBRACE (fase III), de 508 pacientes que recibieron eribulina, presentaron 
alopecia el $45 \%$ en grados 1-2, siendo la segunda toxicidad no hematológica más notificada tras la astenia $^{6}$.

Otras reacciones adversas observadas relacionadas con el fármaco a nivel cutáneo y de anejos fueron prurito, exantema, trastorno de las uñas, sudoración nocturna, eritrodisestesia palmoplantar, sequedad de la piel, eritema e hiperhidrosis.

La CIA es un efecto secundario muy frecuente y se caracteriza por ser no cicatricial (efluvio anágeno) y reversible. La CIA suele ser temporal, con crecimiento del pelo a los 3-6 meses tras finalizar el tratamiento. Sin embargo, la alopecia que presentan las pacientes que están en tratamiento con eribulina se ha evidenciado como transitoria, ya que, paradójicamente, suele ser reversible a las pocas semanas del inicio de tratamiento, a pesar de continuar con este.

La CIA es un efecto secundario que, aunque no es grave, genera un impacto emocional y en la calidad de vida de la paciente. Supone una pérdida de identidad de la imagen corporal, condicionando su relación con el entorno. La pérdida de cabello ocasiona alteraciones físicas, estrés psicológico y disminución de autoestima ${ }^{7,8}$.

\section{BIBLIOGRAFÍA}

1. Asociación Española contra el Cáncer. Cáncer de mama: incidencia. Disponible en: https://www.aecc.es/SobreElCancer/ CancerPorLocalizacion/CancerMama/Paginas/incidencia.aspx

2. Cardoso F, Harbeck N, Fallowfield L, Kyriakides S, Senkus E; ESMO Guidelines Working Group. Locally recurrent or metastatic breast cancer: ESMO Clinical Practice Guidelines for diagnosis, treatment and follow-up. Ann Oncol. 2012;23 Suppl 7:vii11-9.

3. European Medicines Agency (EMA). Assessment report for Halaven (eribulin). Londres: EMA; 2011. Disponible en: http:// www.ema.europa.eu/docs/en GB/document library/EPAR Public_assessment_report/human/002084/WC500105115.pdf

4. Vahdat LT, Pruitt B, Fabian Cl, Rivera RR, Smith DA, Tan-Chiu $E$, et al. Phase II study of eribulin mesylate, a halichondrin B analog, in patients with metastatic breast cancer previously treated with an anthracycline and a taxane. J Clin Oncol. 2009;27(18):2954-61.

5. Cortes I, Vahdat L, Blum JL, Twelves C, Campone M, Roché $\mathrm{H}$, et al. Phase II study of the halichondrin B analog eribulin mesylate in patients with locally advanced or metastatic breast cancer previously treated with an anthracycline, a taxane, and capecitabine. J Clin Oncol. 2010;28(25):3922-8.

6. Cortes J, O'Shaughnessy J, Loesch D, Blum JL, Vahdat LT, Petrakova K, et al.; EMBRACE (Eisai Metastatic Breast Cancer Study Assessing Physician's Choice Versus E7389) investigators. Eribulin monotherapy versus treatment of physician's choice in patients with metastatic breast cancer (EMBRACE): a phase 3 open-label randomised study. Lancet. 2011; 377(9769):914-23.

7. Guerra-Tapia A, González-Guerra E, de la Cruz-Bertolo J. Alopecia female hair integration system: a study of the psychological impact. Med Cutan Iber Lat Am. 2012;40(4):103-8.

8. Crespo Denche AB, Guerra Tapia A. Cuidados del cabello en el paciente en tratamiento con quimioterapia. Más Dermatol. 2013;(19):21-5. 